\title{
PROPOSED SOLCOST MAINTENANCE ACTIVITIES
}

\section{Abstract}

\section{MASTER}

This document provides a short description of work that has been accomplished to date and work in progress. A discussion of the program status as it is currently configured follows and finally proposed work by Solar Environmenatl Engineering Company (SEEC) in its most recently signed contract with the Department of Energy (DOE) is given. Early statements are designed to give the reader a good background so that the suggested SOLCOST maintenance activities, will be more easily understood.

\section{Existing Work}

There are four existing contractors who may or may not be currently funded and have done work on and relating to the SOLCOST computer program. These are International Business Services (IBS), Washington, D.C., Martin Marietta, Denver Office, Johnson Research Center, Huntsville, Alabama and Solar Environmental Engineering Company (SEEC). This particular program configuration was defined while doing work for the Training, Information and Education Branch under the old Solar Applications Branch. The IBS duties were to conduct program scheduling for the prime contract monitor in the DOE, produce manuals and information materials and distribute general information concerning the SOLCOST Program. This was done by setting up booths for trade shows and disseminating information through the mail. They, had no direct responsibility for the technical content of the SOLCOST Program. Martin Marietta, who was the original creator of the SOLCOST Program, is currently involved in creating a passive version, which, as currently defined, will be independent of the SOLCOST Program and will be used for passive system design alone. Its heat analysis 


\section{DISCLAIMER}

This report was prepared as an account of work sponsored by an agency of the United States Government. Neither the United States Government nor any agency Thereof, nor any of their employees, makes any warranty, express or implied, or assumes any legal liability or responsibility for the accuracy, completeness, or usefulness of any information, apparatus, product, or process disclosed, or represents that its use would not infringe privately owned rights. Reference herein to any specific commercial product, process, or service by trade name, trademark, manufacturer, or otherwise does not necessarily constitute or imply its endorsement, recommendation, or favoring by the United States Government or any agency thereof. The views and opinions of authors expressed herein do not necessarily state or reflect those of the United States Government or any agency thereof. 


\section{DISCLAIMER}

Portions of this document may be illegible in electronic image products. Images are produced from the best available original document. 
algorithm will be patterned after Balcomb's SLR approach. They are also involved in creating a photovoltaic stand alone program for design of photovoltaic energy systems. 0ther areas of work include industrial process heat applications which will be accomplished by slight modification to the existing program to include reheat capabilities and advanced collection techniques. The Johnson Research Center in Huntsville, Alabama has recently collected natural gas and electricity cost data to make SOLCOST Program analyses more comprehensive. This utility cost data was collected throughout the country and has been tabulated and furnished to the SOLCOST Service Center maintained by SEEC. SEEC's activities have been to primarily furnish an interface between the users and those who created the code. Much of the feedback from users has gohe into the maintenance activities performed by SEEC in maintaining the SOLCOST Service Center. The Center personnel are responsible primarily for software maintenance and sales and in providing engineering service to users, both in the form of answering questions and.performing analyses for specific applications.

\section{Program Status}

The SOLCOST Program, as it is currently configured, is configured to execute as a batch program only. The SOLCOST program itself is not an interactive program. However, there is a companion program; its interactive interface which, interfaces directly with the user in creating input files for the SOLCOST batch program. The interface is completely interactive in nature and capable of either interrogating the user or prompting the more advanced user and also in editing old input files for new applications. The SOLCOST Program is utilized presently through three avenues: 1) interested users may 
access the code on time-sharing networks such as CYBERNET, Boeing Computer Service or United Computing Systems, or 2) by interfacing with the SOLCOST Service Center and having analyses performed for them or by buying the code from the Service Center and executing it themselves, or 3 ) by going to a third party such as a HVAC firm and having the analysis done for them.

Documentation at the current time exists primarily in the form of a user's manual which provides the information necessary for defining the inputs to the SOLCOST Program. There are also short promotional type information and forms such as a service hot water form and service hot water and space heating forms which aid the user in executing the program for specific applications. One piece of documentation which is greatly needed is a reference manual, which is in the process of being produced by the Martin Marietta Corporation. A programmer's guide and case study book would also be advisable.

\section{SEEC SOLCOST Contract}

The SOLCOST task and deliverables are a part of an overall contract to the DOE which include the Solar Index project as well. There is approximately $\$ 175,000$ total in this contract which is due to expire the last day of September, 1980. The split on money between the Solar Index and SOLCOST is 105 versus: 70, respectively, with the Solar Index project having the priority for funds. This agreement was reached through the contract monitors, Erich Parker for the Solar Index and Vincent Rice for the SOLCOST Program. The primary tasks which SEEC is contracted to deliver through its SOLCOST Service Center activities are engineering support, to perform a feasibility study of small computer applications for the SOLCOST Program, and to provide SOLCOST Program maintenance. A maintenance plan is to be drawn up and reviewed by the Department of Energy for execution throughout the duration of this contract. 
The following is a subjective list of maintenance activities that should be accomplished through maintenance activities allowed by the existing contract. It is obvious in reviewing the following list that there are too many items to be accomplished easily in the time frame and with existing financial support. Following the list will be a proposed prioritization and time line to aid the DOE in determining the actual list of priorities for the SOLCOST computer program.

\section{Documentation}

At the current time, the available documentation for the SOLCOST program is primarily the User's Manual for Version 3.0. This includes many appendices which describe much of the internal methodology of the program, however, a reference manual is needed. Also included in the reference manual should be a software guide for those.individuals who wish to install SOLCOST on their own computing systems. The reference manual should include all of the underlying assumptions and methodology for the various individual systems SOLCOST is capable of analyzing. It should also thoroughly state the method of economic analysis. At the current time, there's a short booklet called "Introduction to SOLCOST" and also two other short booklets for two specific systems, those being the service hot water system and service hot water and space heating system combined. These booklets were produced in 1978 and at the current time have many sections which need to be thoroughly rewritten. There is also possibly a need for additional booklets for which the International Business Services have primary contract responsibility. The SOLCOST Service Center 
has in the past interfaced directly with such efforts. The SOLCOST Service Center proposed to take an aggressive role in the rewriting of the service hot water and service hot water and space heating manuals and then to interface directly with Martin Marietta in the finalization of the reference manual. Martin Marietta at the current time has an extended outline.of that reference manual, but has indicated it is not a line item in their existing contract. It is the intent of the SOLCOST Service Center to somehow finalize this reference manual and make it available for interested users, also to aggressively undertake the rewriting of the service hot water and space heating manuals. Another area of concern here would be to produce a short booklet of expected case studies to possibly include documentation of previous validation activities. Completion of these tasks would produce material greatly beneficial to the usẹr.

\section{Software}

At the current time, the SOLCOST program is executable only on large main frame machines such as CDC, IBM and UNIVAC. A thorough code laundry needs to be accomplished to remove all redundant code and to possibly fix the program up so that it could be executed in conveniently shortened sections so that it will fit easily on smaller machines which do not have the large internal storage capacity of the previously mentioned computers. Another area that is greatl $\dot{y}$ needed for the code is to insert comment statements directly into the code so that it can be much more easily understood by the using community.

\section{Time-Sharing Networks}

Presently, the SOLCOST Program is maintained on CYBERNET, the Boeing Computing Service, United Computing Systems and most recently through the Solar Energy Research Institute and the Argonne Code Center (National Energy Software Center (NESC)).: Solar Environmental Engineering maintains and assists in code dissemination to the SERI, individuals and NESC, where Martin Marietta 
has maintained the code on CYBERNET, the Boeing Computer Service and United Computing Systems. SEEC has reached an agreement with Martin Marietta where it will maintain the code starting sometime this summer on the time-sharing computing networks. The SOLCOST Service Center has primary responsibility for interfacing directly with the using community and answering questions for users who are having trouble executing the code on the time-sharing networks. This has been difficult in the past at times because the SOLCOST Service Center personnel did not place the executable code on these networks. That is why the agreement was pursued and reached where the SOLCOST Service Center would maintain all code sets for dissemination purposes and sales. The Martin Marietta Corporation would become the primary agency for creating new code sets and incorporating far reaching new features. The SOLCOST Service Center would, as a maintenance activity, make field fixes and add new features which are highly desirable and which do not require generation of a great deal of new code.

\section{Solar Systems Maintenance}

Several solar system models could be added easily or modified to reflect state of the art applications. Several of these are as follows. There are several generic service hot water features that are comonly seen in the industry today which are not exactly reflected by the service hot water code in the SOLCOST Program. The two most obvious are the single tank system and thermosyphon systems. The single tank system could be easily modeled with existing software as modified by adding a few lines of code in the subroutine which does the actual system simulation. However, the thermosyphon system would be very difficult to implement at the current time becuase of the lack of understanding of the systems performance. There are computer models available 
which predict the thermosyphon system, but which are not capable of being implemented in a quick executing simplified environment such as the SOLCOST Program. Another system which the SOLCOST Program is ideally suited to analyze is the swimming pool. For experienced users at the current time, swimming pool analysis can be easily performed by the SOLCOST Program as long as any monthly load fraction does not exceed 100\%. The SOLCOST Program is not capable of calculating month to month storage; that is, if excess energy is collected by the solar system than is required to meet the load, then this excess energy is stored in the pool and carried over to the next month. This could be ... handled external to the SOLCOST Program using an energy balance procedure, but proves cumbersome for the average user. Again, this methodology could be easily input into the SOLCOST Program and the required documentation and shortened users manuals generated for easy utilization.

Another area of constant request to the SOLCOST Service Center is to include parasitic energy consumption in the overall solar system performance reports. Since the SOLCOST Program works on a simplified simulation methodology, it will be a simple matter to include parasitic energy estimates in the SOLCOST Program software and then to report these so that their economics can be considered, For liquid systems of the current state of the art design, parasitics probably have little impact. However, parasitic energy consumption for air systems, especially for large blower applications, can become quite substantial. For applications where the heating system is being utilized to collect energy for service hot water, the power comsumption for the blower can easily be greater than the total service hot water energy input for household utilization. 
Currently, the SOLCOST Program is capable of performing analyses for air systems, absorption cooling systems and heat pump systems, both in.a series and parallel configurationn. These models have not been utilized much in the past and have not been kept up to date, for it has been the direction of the DOE not to advertise the existance of the models for general utilization. That should not be conștrued to mean that these particular models cannot be utilized to indicate system sensitivity in a design environment. It should only be construed to mean that they should not be used for analysis purposes. The particular software in the SOLCOST program, which is used in the analysis of these models should be updated and checked whenever possible against other system simulation programs to see if comparable results are obtained. Also, the user's manual does not reflect the utilization of these particular models, but only lists the inputs for those user's who are fairly familiar with the program and know what they are doing. This audience is small, consequently these models are not frequently utilized.

Dr. Kusuda of the National Bureau of Standards has recently produced a simplified heat load technique in FORTRAN which he calls HEAP, Heating Energy Analysis Program. Basically, the methodology uses a steady state sol-air technique for exterior surfaces and includes radiant energy to the conditioned space through glass areas and thermal capacitance of the structure's mass for both a night and a day analysis to get an estimate of the overait heat load of residences. Dr. Kusuda has compared his program against detailed simulation programs such as NBSLD and DOE-2 and has, in his opinion, good comparisons for space heating purposes. He has specifically stated that his methodology is not valid for cooling estimates. The SOLCOST Service Center has obtained this software from Dr. Kusuda and has reviewed it thoroughly. The program at the 
current time is in an easily executable format with the exception that the input-output characteristics of this program are difficult at best to utilize. It contains no structured input section and requires editing of a block data routine for execution of the program. The output is also configured in such a way to where you have to have prior knowledge before reviewing it. The code itself is very clean, containing many comment cards, It is the intent of the SOLCOST Center to transform this code to where it is compatible with the SOLCOST Program and utilizes the SOLCOST Program weather library for data requirements.

- The energy conservation analysis portion of the SOLCOST program assumes that a solar space heating system is an integral part of the system, which, in many cases, may not be the case. Therefore, it would be highly desirable to recanfigure the program in such a way to where the conventional energy conservation measures may be analyzed alone conventionally (the solar system is not included in the overall system package), It may also be advisable to configure a stand alone analysis program for conservation which does not include the solar system space heating at all. This can be accomplished at the current time by defining a solar system that is so small that in essence contributes no usable energy to the structure. However, this approach requires the individual who is doing the design work to be thoroughly based on the SOLCOST methodology so that the result'can be interpreted accurately and with meaning. Another weakness in the energy conservation analysis package is that the program assumes that the financial scenario for energy conservation features are the same as for the solar system. That is, it has the same loan duration and interest rates which may or may not be the case. It would be a simple procedure to add new inputs and break this out. 
I feel a complete sensitivity analysis has never been performed for the SOLCOST Program for the different types of solar space heating systems and al so for the economics portion of the program. SOLCOST Mini-Center personnel are thoroughly aware of which systems are most sensitive and which inputs are most sensitive to design inputs, but this has never been quantified or reported, except for possibly one recent paper for Service Hot Water Systems.

The SOLCOST program does its analysis based on clear and cloudy day radiation values. The hourly radiation levels are calculated per the modified ASHRAE method which includes an overall correction factor known as a clearness number. This clearness number is easily definable and, in general, the user must input an overall clearness number for each location, except for a few locations which have a clearness number recorded on the SOLCOST weather file. The SOLCOST program also has stored internally user definable clearness numbers for each month of the year; monthly clearness numbers are global. That is the same for everywhere and then the annual clearness number for the location is multiplied by the monthly numbers to get an overall scal ing effect. Most recently, several individuals have done a lot of analysis work in determining what the expected clear day radiation levels should be. Inputs for these models include published weather statistics available for most locations throughout the country, inciluding atmospheric pressure, water content, ozone, carbon dioxide and indications of turbidity.. Incorporation of the clear and cloudy day models reflecting this new industry knowledge could be accomplished in several ways. The clear day model could simply be replaced with a more comprehensive one which is now available; or, in an effort to conserve computation time for each SOLCOST analysis, 
clearness numbers could be calculated beforehand for each location for each month and recorded in the weather file.

Currently, the SOLCOST Program assumes that the load is uniform throughout the month. Situations where the load is predominant, for say, five days of the week and then near zero for two days of the week, is not a user definable option. Individuals, however, who are thoroughly familiar with the SOLCOST program are capable of performing such an analysis by doing two different SOLCOST Program evaluations for a specific system for the two different loads and then taking a weighted average of the results. to get the expected energy input from the solar system. Two things can be done: 1) a dócument could be produced which explains to the user the methodology needed to accomplish.such a task using the SOLCOST program as it currently exists, or 2) modify the program so that it will accomplish this task automatically when desired. The first methodology makes it virtually impossible to get realistic economic. expectations out of the SOLCOST program, and if they were needed they would have to be calculated by hand or with some other software. A new methodology would accomplish this automatically, but the cost to be paid would be the generation of the appropriate software and program checkout.

\section{Economic Update.}

There are several fine points in the economic analysis of the SOLCOST Program that need to be updated and refined. The first is to allow for the possibility of different economic scenarios for a conventional and a solar system. Currently, the long term interest rate and down payment are considered for both the reference system and the solar system which is being analyzed on an economic standpoint. It is very likely that the loan period and interest rate would be 
different. For example, a space heating system would be considered part of the structure in an economic sense and an add-on solar system for a residential application, or even small business application, would be considered a retrofit application. A second item in consideration is to update the default values to reflect currently available incentives in the industry today. Also, a complete review of state credits need to be accomplished to ensure that the SOLCOST Program is capable of analyzing as many combination of credits as possible. Another item would be to include the possibility of incorporating different auxiliaries in combined service hot water and space heating systems. For example, it is possible that the service hot water system auxiliary would be electricity and the space heating auxiliary: would be natural gas. Currently, the SOLCOST Program as well as FCHART as far as that goes, requires that these auxiliaries be the same. This could also be construed to include parasitic energy consumption such as electricity for pumps, fans and blowers which are not part of the reference system in the overall economic calculation.

One of the most important parameters which has been eliminated from a SOLCOST economic analysis is a calculation of the resale value of the solar system for residential applications. If a homeowner wishes to sell his house five years down the road, which is commonly the case, the SOLCOST Program does not consider the fact that the homeowner will be able to recoup much of the cost of' the system, if not the complete cost of the system at that time of the resale. Value of the structure, even though the resale money is not worth what it is in today's dollars, will affect the overall economics of the system significantly. Resale value is included in the salvage value calculation in business applications. 
Currently, the SOLCOST Program is capable of including demand level charges in calculating the economic feasibility of a solar system. However, the user must input the demand level that is likely to be achieved for all time which is used each month to estimate the total auxiliary costs of electricity. This is not realistic, for most electric heating systems are stepped so that it is unlikely that in May when heating comes on that more than the first step rate utilization rate for an auxiliary electric furnace will be utilized. Methodologies need to be reviewed so as to estimate the maximum load for each given month so as to estimate this utilization demand rate more closely.

\section{Passive/Active Combined System Optimization}

Doug Balcomb of Los Alamos has recently published regression equations for determining the energy input from passive heating systems, primarily for single zone applications. There are situations where it is advantageous to include active and passive systems together. Many people have indicated that the way to estimate the active space heating contribution is to simply modify the net load and then pretend that the passive system. is not there and calculate the energy input from the active system via FCHART or SOLCOST or some other simplified heating solar heating system evaluation program. This may be appropriate for passive systcms with low load fracliuns. However, when the system is sized large enough to where there is no active energy requirement on sunny days, then this methodology becomes less and less accurate. For example, on a sequence of sunny days, all the active system would be doing is keeping the storage energy charged at the maximum it can achieve and then when a cloudy day comes it discharges energy to the conditioned space. The SOLCOST methodology or the FCHART methodology more or less assumes that the load is uniformly distributed 
over the months. The Martin Marietta Corporation is at the current time producing a compatible SOLCOST Program for analysis of passive systems. This program is to utilize the SLR methodology and is to stand independently of the currently established SOLCOST Program. However, it is desirable to be able to analyze combined active and passive systems. This could be approximated by utilizing SOLCOST to analyze space heating systems with two loads. One load would be a sunny day expected load and the other load would be the cloudy day expected load and then weighting the results via the percent of sunshine, where the weighted total load will come out to be the leftover load that the passive system is rot capable of supplying. This is one methodology in approximating the active component contribution coupled with a passive space heating. A significant amount of work would need to be accomplished to determine the expected impact of the methodology and then to compare predictions versus established software capable of evaluating combined systems. For example, TRNSYS or DOE-2, or possibly other simulation programs which could be configured to analyze these systems. It is desirable at this time to devise such a simplified methodology. It is not proposed that evaluation of this methodology is to take place under the current maintenance schedule for time and money are not available. It is only advisable to define the methodology and see how it differs from existing methodologies.

\section{Date Base}

When the Mini-Center was first configured in 1978, a. small data base was established to support Mini-Center activities. This particular data base has not been supported actively and is only used occasionally to supply missing information for users who submit SOLCOST forms for analyses who have left out certain information. The most common missing information is the collector 
parameters. For specific collectors, the data base is capable of supplying this information. It is time to reaccomplish an update of the information contained in the data base and to further refine the management systems so it is more portable. The management system at the current time has been configured in such a way to where it is only executable on CDC machines. 
SCOPE OF WORK

The SOLCOST Program, as it currently stands, has been described and following is the time line and subject areas that work will be devoted to during execution of the current contract. The following table references subject areas mentioned in the previous discussion in which it would be desirable to devote efforts in support of the SOLCOST Program. It is intended to support as many of these areas as possible, and some of them have been flagged as continous on-going work and specific contract requirements. The items in the list in vertical form as listed in prioritized order and following is a list of areas that will definitely be attacked during the execution of the contract. The other areas will be approached as recommended by the Department of Energy and as time and money are available. The list is as follows:

1. Handbooks

2. Bugs and Spruce-ups

3. Small Computer Application

4. User's Support

5. Data Base Upkeep

6. Swiming Pool Ability

7. Heat Load Analysis Capabilities

The work will be accomplished uniformly (level effort) throughout the.duration of the contract. 


\section{Proposed SOLCOST Maintenance Activities}

Documentation

1. SOLCOST Overview

2. Service Hot Water Book

3. Space Heating Book

4. User's Guide

5. Refererice Manual

6. Program Manual

\section{Case Study} Book

\section{Code}

1. Bugs $^{+}$

2. Shorten

3. Sma11

Computer Applications*

4. Clean ${ }^{+}$

5. Comments

\section{Networks}

1. User Support ${ }^{+}$

2. New

Releases

2. Heatload Analys is

3. Parasitics

4. Conservation Alone

5. Sensitivity Analys is

6. Radiation Subroutine

7. Varying Load Pattern

8. Constant

Storage

Size
Studies

1. Different Scenarios

2. Incentives

3. Demand Rate

4. Resale Value
1. Combined

Passive
Data Base

1. Support ${ }^{+}$

2. Update 